\title{
Chitosan derivatives targeting lipid bilayers: Synthesis, biological activity and interaction with model membranes
}

\author{
Danubia Batista Martins ${ }^{\mathrm{b}}$, Fábio Domingues Nasário ${ }^{\mathrm{a}}$, Laiz Costa Silva-Gonçalves ${ }^{\mathrm{c}}$, \\ Vera Aparecida de Oliveira Tiera ${ }^{a}$, Manoel Arcisio-Miranda ${ }^{c}$, Marcio José Tiera ${ }^{\mathrm{a}}$, \\ Marcia Perez dos Santos Cabrera ${ }^{\mathrm{a}, \mathrm{b}, *}$ \\ ${ }^{a}$ Departamento de Química e Ciências Ambientais, Universidade Estadual Paulista (Unesp), Instituto de Biociências Letras e Ciências Exatas (Ibilce), Câmpus São José do \\ Rio Preto, R. Cristóvão Colombo, 2265, 15054-000, SP, Brazil \\ ${ }^{\mathrm{b}}$ Departamento de Fisica, Universidade Estadual Paulista (Unesp), Instituto de Biociências Letras e Ciências Exatas (Ibilce), Câmpus São José do Rio Preto, R. Cristóvão \\ Colombo, 2265, 15054-000, SP, Brazil \\ ${ }^{\mathrm{c}}$ Laboratório de Neurobiologia Estrutural e Funcional (LaNEF), Departamento de Biofísica, Universidade Federal de São Paulo, R. Botucatu, 862, 04023-062, São Paulo, \\ SP, Brazil
}

\section{A R T I C L E I N F O}

\section{Keywords:}

Quaternized chitosan

Chitosan-lipid bilayer interaction

Hydrophobic/hydrophilic balance

Lytic activity

Antimicrobial and tumoricidal activities

Charge cluster mechanism

\begin{abstract}
A B S T R A C T
The antimicrobial activity of chitosan and derivatives to human and plant pathogens represents a high-valued prospective market. Presently, two low molecular weight derivatives, endowed with hydrophobic and cationic character at different ratios were synthesized and characterized. They exhibit antimicrobial activity and increased performance in relation to the intermediate and starting compounds. However, just the derivative with higher cationic character showed cytotoxicity towards human cervical carcinoma cells. Considering cell membranes as targets, the mode of action was investigated through the interaction with model lipid vesicles mimicking bacterial, tumoral and erythrocyte membranes. Intense lytic activity and binding are demonstrated for both derivatives in anionic bilayers. The less charged compound exhibits slightly improved selectivity towards bacterial model membranes, suggesting that balancing its hydrophobic/hydrophilic character may improve efficiency. Observing the aggregation of vesicles, we hypothesize that the "charge cluster mechanism", ascribed to some antimicrobial peptides, could be applied to these chitosan derivatives.
\end{abstract}

\section{Introduction}

The demand for biodegradable and non-toxic antimicrobials is an increasing field of research for controlling plant pathogens and a variety of harmful microorganisms to human health. Chitosan has been one of the most studied polysaccharides for this purpose. To provide additional properties and applications to chitosan, the synthesis and characterization of new derivatives has been extensively explored through its functionalization with hydrophobic and hydrophilic groups (Benediktsdóttir, Gudjónsson, Baldursson, \& Másson, 2014; Huo et al., 2010). Special attention has been given to its use in antimicrobial coatings (Kong, Chen, Xing, \& Park, 2010; Rabea, Badawy, Stevens, Smagghe, \& Steurbaut, 2003), fungicides (Rabea et al., 2005; Radulescu et al., 2015), bactericides (Li et al., 2011; Seo, King, Prinyawiwatkul, \& Janes, 2008), packaging materials (González-Aguilar et al., 2009), and crop protection (Bautista-Baños et al., 2006). Regarding its antimicrobial activity, the mechanism of action is influenced by intrinsic parameters, such as the molecular weight, the degree of deacetylation, the amphiphilic nature, the chelating ability and the physical state (Kong et al., 2010). Also, its activity is dependent on the type of microorganism and other environmental conditions as $\mathrm{pH}$ and ionic strength (Kong et al., 2010; Rabea et al., 2003).

In general, the antimicrobial activity of plain chitosan is more effective at $\mathrm{pH} \ll 6.0$ due to protonation of the amino groups, which provides water solubility and a positive charge density to the macromolecular chain, enabling stronger interactions with the cell membrane of the microorganisms (Kong et al., 2010). Although the exact mechanism of action is unknown, it is well accepted that this interaction may lead to the damage of the cell membrane and leaking of the intracellular constituents (Jung, Kim, Choi, Lee, \& Kim, 1999; Xing, Chen,

\footnotetext{
Abbreviations: PC, egg-phosphatidylcholine; PG, egg-phosphatidylglycerol; PS, phosphatidyl-L-serine

* Corresponding author at: Departamento de Química e Ciências Ambientais, IBILCE, UNESP, R. Cristóvão Colombo, 2265, 15054-000 São José do Rio Preto, SP, Brazil.

E-mail addresses: danubiab4@hotmail.com (D.B. Martins), fabio.nasario@iqm.unicamp.br (F.D. Nasário), laizdacostasilva@yahoo.com.br (L.C. Silva-Gonçalves), verapoli@ibilce.unesp.br (V.A. de Oliveira Tiera), arcisio.miranda@unifesp.br (M. Arcisio-Miranda), mjt@ibilce.unesp.br (M.J. Tiera),

cabrera.marcia@gmail.com, marciap@ibilce.unesp.br (M.P.dos Santos Cabrera).
} 
Liu, Cha, \& Park, 2009). The activity may occur even at low concentrations $\left(\ll 0.2 \mathrm{~g} \mathrm{~L}^{-1}\right)$ through the binding to negatively charged surface of the microorganisms, causing agglutination, while for higher concentrations the binding may also provide a positive surface maintaining the cells in suspension (Sudarshan, Hoover, \& Knorr, 1992).

The molecular weight is considered one the most important parameters for providing antibacterial and antifungal activity and has been extensively studied (Seyfarth, Schliemann, Elsner, \& Hipler, 2008). However, the results found in the literature are controversial; they depend on the physical state (in solution or solid coating) and the type of fungi or bacteria used (González-Aguilar et al., 2009; Guo et al., 2008; Xing et al., 2008). For example, quaternary derivatives have been reported to exhibit good antifungal activities against Botrytis cinerea Pers. and Colletotrichum lagenarium, and the results indicated that high molecular weight derivatives were more efficient than the low ones (Guo et al., 2008). Also, high activity has been reported against Candida species and Escherichia coli for oligomeric chitosans (Kulikov et al., 2014).

Based on studies using phospholipid vesicles as model membranes it has been shown that the interaction of chitosan with large unilamellar vesicles resulted in positively decorated vesicles due to chitosan adsorption onto the membrane. It is suggested that the adsorption process involves both electrostatic and hydrophobic interactions (Quemeneur, Rinaudo, \& Pépin-Donat, 2008). Moreover, alterations in the vesicles structure have been shown to take place by insertion of chitosan chains into the membranes (Fang, Chan, Mao, \& Leong, 2001; Mertins, Cardoso, Pohlmann, \& da Silveira, 2006; Mertins, Sebben, Pohlmann, \& da Silveira, 2005).

To produce highly active derivatives against bacteria species, the attaching of hydrophobic groups (de Oliveira Pedro et al., 2013; Viegas de Souza et al., 2013) and biologically active moieties is an important strategy (Fernandez-Megia, Novoa-Carballal, Quiñoá, \& Riguera, 2007). The limitation of hydrophobic derivatives is mainly due to their poor aqueous solubility at neutral $\mathrm{pH}$ and quaternary derivatives seem to be a good alternative to overcome this limitation (Rúnarsson et al., 2010). We have previously shown that the interaction of chitosan and its $N$ dodecyl and poly(ethylene glycol) derivatives with 1,2-dipalmitoyl-snglycero-3-phosphocholine vesicles altered the gel-liquid crystalline phase transition temperature and decreased both the enthalpy and cooperativity of the phase transition (de Oliveira Tiera, Winnik, \& Tiera, 2010). These results indicate that adsorption on vesicles surface and incorporation of these amphiphilic derivatives into the lipid bilayer could lead to vesicles disruption and reorganization (Mertins \& Dimova, 2013).

Considering the importance of microbial membranes as the target for new drugs to avoid the rapid development of resistance mechanisms, we engineered cationic derivatives of chitosan with features that could profit from this advantage for new antimicrobial or antitumor agents. From highly deacetylated chitosans of low molecular weight we prepared compounds that were subjected to a reductive amination reaction with dodecylaldehyde, and subsequently quaternized with methyl iodide to provide solubility at neutral $\mathrm{pH}$. Then, we assessed the antimicrobial activity toward Gram-positive and Gram-negative strains and the cytotoxicity toward human cervical carcinoma cells. The results obtained in the bio-assays lead us to investigate the interaction of the precursors and derivatives with model membranes of different lipid compositions that mimic bacterial (Lohner \& Prenner, 1999; Matsuzaki, Sugishita, Fujii, \& Miyajima, 1995), tumoral (Dobrzyńska, SzachowiczPetelska, Sulkowski, \& Figaszewski, 2005; Zwaal, Comfurius, \& Bevers, 2005) and erythrocyte membranes (Lohner \& Prenner, 1999). This novel and embracing approach helps to understand the mode of action underlying these activities of chitosan and derivatives, which are underexplored and neither clear nor easy to comprehend (Verlee, Mincke, \& Stevens, 2017). Considering the hypothesis that the cationic charge of these compounds will make them target the anionic membranes, we determined their binding through zeta potential measurements. Then, their ability to disturb the model membranes was evaluated by the lytic activity and changes of the lipid packing monitored in fluorometric experiments. Using dynamic light scattering we verified the clustering ability of the compounds. The results are discussed in relation to the degree of substitution of the derivatives, which impart different hydrophobic/hydrophilic features, and interpreted under the light of the mechanisms of action similarly proposed for cationic antimicrobial peptides as the charge cluster mechanism (Epand, Maloy, Ramamoorthy, \& Epand, 2010). The high local density of cationic charges in chitosans clusters anionic phospholipids away from the zwitterionic ones, disturbing the barrier properties of the membranes, promoting leakage and also recruiting other vesicles for charge neutralization.

\section{Experimental section}

\subsection{Materials}

Chitosan, 85\% DDA was purchased from Polymar Co., Fortaleza, Ceará, Brazil. Dodecylaldehyde, methyl iodide, sodium cyanoborohydride, deuterium chloride (35\%) in deuterium oxide, deuterium oxide, 5,6-carboxyfluorescein (CF), diphenylhexatriene (DPH), cholesterol, and 3-(4,5-dimethylthiazol-2-yl)-2,5-diphenyltetrazolium bromide (MTT) were purchased from Sigma Aldrich (St. Louis, MO). Egg L- $\alpha$ phosphatidylcholine (PC) and egg L- $\alpha$-phosphatidylglycerol sodium salt (PG), 1-palmitoyl-2-oleoyl-sn-glycero-3-phospho-L-serine sodium salt (PS) and cardiolipin (CL) were supplied by Avanti Polar Lipids (Alabaster, AL). Dulbeccós modified eagle medium (DMEM), fetal bovine serum (FBS), L-glutamine, and penicillin/streptomycin were purchased from Life Technologies (São Paulo, Brazil). SpectraPore membranes (Spectrum Laboratories, Rancho Dominguez, CA) were employed for dialysis. All solvents and reagents were of high quality analytical grade and used as received. Water was deionized or ultrapure.

\subsection{Synthesis of the derivatives of chitosan}

The synthesis is summarized in Fig. SI1. The derivatives were synthesized using 98\% deacetylated (by ${ }^{1} \mathrm{H}$ NMR) and degraded chitosan sample (CH2; Mw $12.0 \mathrm{kDa}$ and Mw/Mn 1.34; Fig. SI2a), which was obtained following a previously described procedure (Tiera et al., 2006). Shortly, CH2 was subjected to hydrophobic modification through reductive amination with dodecylaldehyde (Desbrières, Martinez, \& Rinaudo, 1996), and the dodecylated derivative (CHDD) was quaternized as detailed elsewhere (Rúnarsson, Holappa, Jónsdóttir, Steinsson, \& Másson, 2008).

To produce a derivative containing $20 \%$ dodecyl groups (CHDD20), $0.5 \mathrm{~g}$ of $\mathrm{CH} 2$ was dissolved in a mixture of $90 \mathrm{~mL}$ acetic acid $2 \%$ and $50 \mathrm{~mL}$ ethanol. The $\mathrm{pH}$ was adjusted to 5.7 and, while stirring, $0.15 \mathrm{~mL}$ of dodecylaldehyde dissolved in $20 \mathrm{~mL}$ ethanol was drop wise added to the reaction mixture. It was continuously stirred for $24 \mathrm{~h}$ at room temperature; sodium cyanoborohydride (6:1, $\mathrm{NaCNBH}_{3}: \mathrm{NH}_{2}$, mol mol${ }^{-1}$ ) was added after the first hour. Thereafter, the reaction mixture was precipitated by adding aqueous $\mathrm{NaOH}\left(1.0 \mathrm{~mol} \mathrm{~L}^{-1}\right)$, centrifuged, washed with water and methanol and dried at $50{ }^{\circ} \mathrm{C}$ for $24 \mathrm{~h}$ (Table 1). The quaternization using methyl iodide (Rúnarsson et al., 2008) was carried by dispersing $0.5 \mathrm{~g}$ of the CHDD20 in $25 \mathrm{~mL}$ $\mathrm{DMF} /$ water (50:50) under vigorous magnetic stirring. Based on the amino groups content of CHDD20, sodium hydroxide and methyl iodide were added to the solution at equivalent ratios of $3: 1$ and $6: 1$, respectively. Then, the mixture was stirred at room temperature and after $48 \mathrm{~h}$ the addition was repeated at the same ratio. This step was again repeated twice to generate $\mathrm{CH} 30$ and three times for $\mathrm{CH} 50$. The $\mathrm{pH}$ was monitored and maintained above 7.0 by addition of solid sodium hydroxide (Rúnarsson et al., 2008). The reaction mixture was dialyzed (using a membrane of $3500 \mathrm{~g} \mathrm{~mol}^{-1}$ MWCO) against water for 5 days 
changing the dialysis water twice a day. The product was freeze dried in a lyophilizer (Thermo Electron Corporation, USA), and subsequently purified in a Soxhlet system using chloroform to remove non-reacted dodecylaldehyde. The derivatives were characterized by ${ }^{1} \mathrm{H}$ NMR, recorded using a Bruker ARX-500 $500 \mathrm{MHz}$ spectrometer.

\subsection{Preparation of chitosan and derivatives solutions}

Chitosan derivatives $(\sim 1 \mathrm{mg})$ were dissolved in acetic acid $0.01 \mathrm{~mol} \mathrm{~L}^{-1}$ at the stoichiometric amount plus $10 \%$ excess considering the fraction of protonable amine groups. The solution was kept under stirring for at least $12 \mathrm{~h}$ at room temperature. This stock solution was diluted with equal volume of buffer, Tris- $\mathrm{HCl} 30 \mathrm{mM}$ for the dye leakage experiments and biological tests or buffer citrate/phosphate (10 mmol L $\left.{ }^{-1} \mathrm{C}_{6} \mathrm{H}_{8} \mathrm{O}_{7}, 10 \mathrm{mmol} \mathrm{L}^{-1} \mathrm{Na}_{2} \mathrm{HPO}_{4}, 150 \mathrm{mmol} \mathrm{L}^{-1} \mathrm{NaF}\right) \mathrm{pH}$ 5.5 for the biophysical experiments.

\subsection{Bactericidal assay}

The antimicrobial activity was assayed by the suppression of growth of E. coli (DH5a strain, Invitrogen) and S. aureus (ATCC 25923) incubated with different concentrations of chitosan derivatives. Bacteria were grown in Luria-Bertani broth liquid medium to an $\mathrm{OD}_{600}$ of 0.3 $\left(240 \times 10^{6} \mathrm{CFU} \mathrm{mL}^{-1}\right)$. Samples were diluted to a concentration of $24 \times 10^{6} \mathrm{CFU} \mathrm{mL}{ }^{-1}$ and incubated for $3 \mathrm{~h}$ at $37^{\circ} \mathrm{C}$ with different concentrations of chitosan derivatives. Next, the $\mathrm{OD}_{600}$ of the samples was measured in a Spectrophotometer Hitachi U-2910 (Hitachi High Technologies, San Jose, USA) or in a FlexStation 3.0 (Molecular Devices, Sunnyvale, USA).

\subsection{Cell cytotoxicity}

The cell toxicity was assessed by the 3-(4,5-dimethylthiazol-2-yl)2,5-diphenyltetrazolium bromide (MTT) reduction inhibition assay (Berridge \& Tan, 1993). Human cervical carcinoma (HeLa) cells were cultured at $37{ }^{\circ} \mathrm{C}$ in humidified air with $5 \% \mathrm{CO}_{2}$ in DMEM medium supplemented with $10 \%$ fetal bovine serum, $2 \mathrm{mmol} \mathrm{L}^{-1}$ glutamine, 100 units $\mathrm{mL}^{-1}$ penicillin and $100 \mathrm{mg} \mathrm{mL}^{-1}$ streptomycin. The cells were plated at a density of 5000 cells per well in 96-well plates in $100 \mu \mathrm{L}$ of culture medium. The cells were incubated for $24 \mathrm{~h}$ with the desired concentration of chitosan derivatives. Next, $10 \mu \mathrm{L}$ of MTT $\left(10 \mathrm{mg} \mathrm{mL}^{-1}\right)$ were added to each well. After $2 \mathrm{~h}, 100 \mu \mathrm{L}$ of DMSO were added to each sample that was incubated at room temperature until complete cell lysis. The absorbance of the formazan was measured at $570 \mathrm{~nm}$ in Ultra Microplate Reader EL 808 (Bio-Tek Instruments).

\subsection{Self-association: determination of the Critical Aggregation Concentrations (CAC)}

The aggregation properties of chitosan and derivatives were investigated using pyrene as a probe in a Cary Eclipse - Varian fluorescence spectrometer, at $25.0 \pm 0.1{ }^{\circ} \mathrm{C}$. Stock solutions were added to a citrate/phosphate buffered solution of pyrene $\left(5.0 \times 10^{-7} \mathrm{~mol} \mathrm{~L}^{-1}\right.$; $\mathrm{pH}$ 5.5) under magnetic stirring, and fluorescence spectra were recorded after each addition. The ratio between the fluorescence intensities of peaks I $(375 \mathrm{~nm})$ and III $(386 \mathrm{~nm})$ of pyrene emission spectrum $\left(\mathrm{I}_{1} / \mathrm{I}_{3}\right.$ ratio) was used to evaluate the polarity of the local environment and to determine the CAC (Vieira, Moscardini, Tiera, \& Tiera, 2003). Pyrene was excited at $310 \mathrm{~nm}$ (slit $20 \mathrm{~nm}$ ) and the emission (slit $1.5 \mathrm{~nm}$ ) was recorded from 350 to $550 \mathrm{~nm}$.

\subsection{Large unilamellar vesicle (LUV) preparations}

Lipid films at the desired composition were prepared by mixing aliquots of the stock solutions of phospholipids, evaporating the solvent under a gentle nitrogen flow, and further drying under vacuum for at least $3 \mathrm{~h}$. Then, films were hydrated with appropriate buffers (either $10 \mathrm{mmol} \mathrm{L}^{-1}$ Tris-HCl, 1 mmol L ${ }^{-1} \mathrm{Na}_{2}$ EDTA, containing $25 \mathrm{mmol} \mathrm{L}^{-1}$ CF, pH 7.4 for the CF-filled LUVs, or $10 \mathrm{mmol} \mathrm{L}^{-1} \mathrm{C}_{6} \mathrm{H}_{8} \mathrm{O}_{7}$, $10 \mathrm{mmol} \mathrm{L}^{-1} \mathrm{Na}_{2} \mathrm{HPO}_{4}, 150 \mathrm{mmol} \mathrm{L}^{-1} \mathrm{NaF}, \mathrm{pH} 5.5$ in the biophysical experiments) and vortex mixed at room temperature rendering solutions around $10 \mathrm{mmol} \mathrm{L}^{-1}$ lipid concentration. The actual lipid concentration was confirmed by phosphorus analysis (Rouser, Fkeischer, \& Yamamoto, 1970). LUVs were obtained within a diameter range of $105-130 \mathrm{~nm}$ after 6 times extrusion through $400 \mathrm{~nm}$ pore size polycarbonate membranes (Nuclepore Track-etch Membrane, Whatman, USA), followed by 11 times extrusion through $100 \mathrm{~nm}$ pore size polycarbonate membranes using a Liposofast mini-extruder (Avestin Inc., Ontario, Canada), at room temperature. LUVs containing entrapped carboxyfluorescein (CF) were separated from free CF using a Sephadex G25 M gel column (PD-10, GE Healthcare Life Sciences) and eluted with Tris-HCl buffer containing $1 \mathrm{mmol} \mathrm{L}^{-1} \mathrm{Na}_{2}$ EDTA and $150 \mathrm{mmol} \mathrm{L}^{-1}$ $\mathrm{NaCl}, \mathrm{pH}$ 7.4. LUVs were used within $24 \mathrm{~h}$ of preparation, kept under refrigeration $\left(8{ }^{\circ} \mathrm{C}\right)$ and protected from light. Vesicle size was confirmed by dynamic light scattering (DLS) with a Zetasizer Nano ZS (Malvern Instruments, Worcestershire, U.K.). LUVs of the following lipid composition (molar ratio) were prepared: 70:30 PC/PG, 50:50 PG/CL, 60:20:20 PC/PS/Chol and 100\% PC, mimicking respectively the membranes of Gram-negative and Gram-positive bacteria (Lohner \& Prenner, 1999; Matsuzaki et al., 1995), tumors (Dobrzyńska et al., 2005; Zwaal et al., 2005) and erythrocytes (Lohner \& Prenner, 1999).

\subsection{Dye leakage}

Experiments were conducted in an ISS PC1 spectrofluorometer (ISS, Urbana Champaign, IL, USA), at $25^{\circ} \mathrm{C}$, using a $1 \mathrm{~cm}$ quartz cell. A $100 \mu \mathrm{mol} \mathrm{L}^{-1}$ suspension of CF-filled LUVs was obtained by diluting the LUVs preparation with the $10 \mathrm{mmol} \mathrm{L}^{-1}$ Tris-HCl buffer, $\mathrm{pH} 7.4$ described above. An aliquot of the chitosan derivative stock solution was added to the magnetically stirred vesicle suspension. CF fluorescence intensity was monitored at $520 \mathrm{~nm}$ wavelength with a 0.5 slit width (excitation wavelength $490 \mathrm{~nm}$ and $1.0 \mathrm{~nm}$ slit width). The percentage of $\mathrm{CF}$ released was calculated as \% leakage $=100 \times\left(\mathrm{F}-\mathrm{F}_{0}\right)$ / $\left(F_{100}-F_{0}\right)$, where $F$ is the observed fluorescence intensity, $F_{0}$ and $F_{100}$ are, respectively, the fluorescence intensities in the absence of polycations and at $100 \%$ leakage, as determined by the addition of $20 \mu \mathrm{L}$ of $10 \%$ Triton $\mathrm{X}-100$ solution. $\mathrm{F}_{100}$ has been corrected for the corresponding dilution factor.

\subsection{Size and zeta potential determinations}

The Zetasizer Nano ZS (Malvern Instruments, Worcestershire, U.K.) was used to determine aggregation of LUVs induced by the chitosan derivatives and precursors, through its size mode and the corresponding zeta potential changes to verify the binding of the same samples to the LUVs. Chitosan derivative solutions were prepared in buffer, $\mathrm{pH} 5.5$, in plastic vials and an aliquot of the vesicle suspension was added to a final concentration of $100 \mu \mathrm{mol} \mathrm{L}{ }^{-1}$. Each preparation was first equilibrated for $30 \mathrm{~min}$ at $25^{\circ} \mathrm{C}$ and then transferred to a disposable cuvette for the size evaluation. Afterward, the same preparation was transferred to a DTS10700 cell (Malvern Instruments) for zeta potential measurement.

\section{Results}

\subsection{Synthesis and characterization}

Chitosan derivatives (Fig. 1) were prepared from CH2 sample in a two steps process. I) After the reductive amination reaction with dodecyl aldehyde, the ${ }^{1} \mathrm{H}$ NMR spectra of the generated derivative, CHDD20, exhibit three new signals after substitution by the dodecyl group: a singlet at $1.30 \mathrm{ppm}$, corresponding to the protons of the methyl 
a
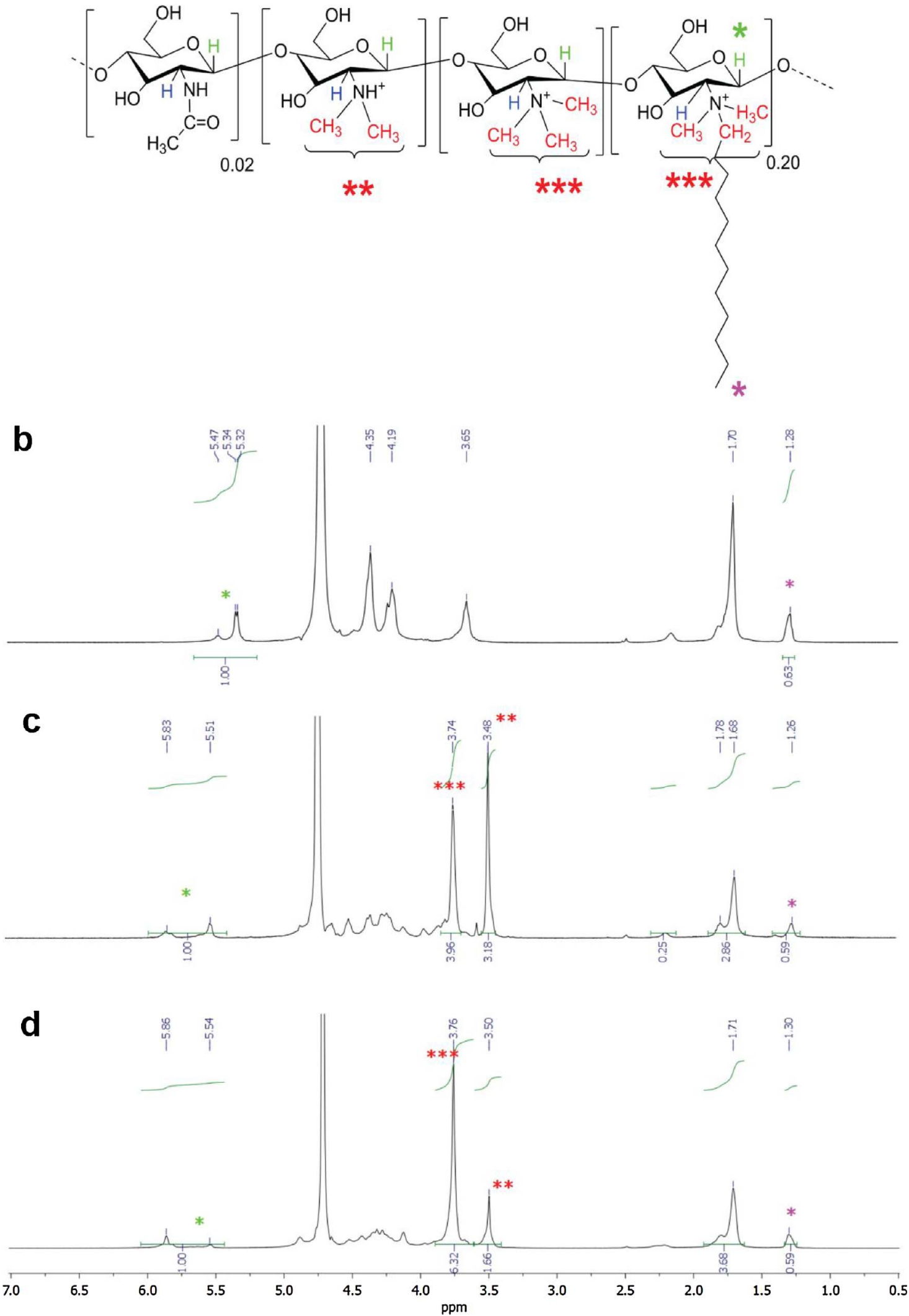

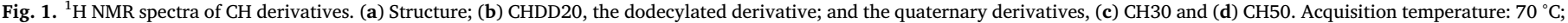
solvent: $\mathrm{D}_{2} \mathrm{O} / \mathrm{DCl}(1 \%)$. (**) dimethylated and $(* * *)$ trimethylated groups. 
group on the dodecyl chain; a signal at $1.70 \mathrm{ppm}$ corresponding to protons in the hydrocarbon chain; and that at $2.15 \mathrm{ppm}$ corresponding to the methylene protons of the carbon atom linked to the amino group of chitosan (Fig. 1b, CHDD20). The attachment of dodecyl groups to $\mathrm{CH} 2$ framework alters the ${ }^{1} \mathrm{H}$ NMR spectrum most notably in respect to the anomeric protons of substituted and non-substituted glucosamine units. This signal undergoes a downfield shift from 5.34 to $5.47 \mathrm{ppm}$, which results from substituted glucosamine rings. The integrated areas of the signal at $1.30 \mathrm{ppm}$ and those assigned to the anomeric protons of chitosan chains at 5.20-5.60 ppm were used to calculate the degree of substitution by DD by Eq. (1) (Desbrières et al., 1996).

$D S_{D o d}=\frac{I_{C H_{3}}}{I_{H_{1}}+I_{H_{1 s}}}$

II) After the quaternization step, the reacted CHDD20 with $\mathrm{CH}_{3} \mathrm{I}$, produced two different methylated derivatives, $\mathrm{CH} 30$ and $\mathrm{CH} 50$, whose ${ }^{1} \mathrm{H}$ NMR spectra are shown in Fig. $1 \mathrm{c}$ and d, respectively. The quaternization reaction takes place on the free and dodecylated amino groups as indicated in Fig. 1a. The degrees of substitution for dimethylated (\% GDM) and trimethylated units (\% GTM) were estimated from the signals appearing at 3.48 and $3.74 \mathrm{ppm}$. \% GTM was estimated taking into account the contribution of the trimethyl groups of both, dodecylated and non-dodecylated units. The signal of trimethylated amino groups overlaps the signal of the $\mathrm{H}-2$ protons of the glucosamine rings, appearing shifted to downfield in the range of $3.67-3.85 \mathrm{ppm}$ (Rúnarsson et al., 2007). Therefore, GDM and GTM were estimated using the relationships 2 and 3 (Rúnarsson et al., 2008).

$G D M=\frac{A_{\mathrm{N}\left(\mathrm{CH}_{3}\right)_{2}}}{A_{H 1} x 6}$

$G T M=\frac{\left(A_{\mathrm{N}\left(\mathrm{CH}_{3}\right)_{3}}-1\right)}{A_{H 1} \times 10.8}$

where $A_{H 1}$ refers to the signals at $5.40-5.90$ ppm range due to the anomeric protons of substituted and non-substituted glucosamine residues. The factor " -1 " in Eq. (3) numerator subtracts the contribution of the H-2 hydrogen signal, and the factors " 6 " and " 10.8 " refer to protons of the dimethylated and trimethylated units, respectively. The term 10.8 accounts for nine protons from trimethylated amino groups plus the contribution arising from methyl groups inserted on dodecylated amino groups.

To verify the importance of the hydrophobic moiety for the activity of the chitosan derivatives a quaternized compound, $\mathrm{MeCH} 2$, was also produced (Fig. SI2b). The ${ }^{1} \mathrm{H}$ NMR spectrum of MeCH2 exhibited new signals, most notably at $3.72,3.47$ and $3.29 \mathrm{ppm}$, corresponding to trimethylated, dimethylated and monomethylated units, respectively, that confirmed the methylation of deacetylated chitosan. The attachment of methyl groups brings further changes in the resonances of protons in close proximity to the substitution site, specifically, protons $\mathrm{H}-1$ and $\mathrm{H}-2$ of the glucosamine unit. The anomeric proton signal undergoes a downfield shift, from $5.3 \mathrm{ppm}$ to $5.5 \mathrm{ppm}$, while the signal at $3.61 \mathrm{ppm}$ shifts to $3.79 \mathrm{ppm}$. The substitution degrees for trimethylated and dimethylated units were estimated using the relationships 2 and 3 and the monomethylated units were estimated using the relationship.

$G D M=\frac{A_{\mathrm{NCH}_{3}}}{A_{H 1} \times 3}$

As the quaternary derivatives, $\mathrm{CH} 30$ and $\mathrm{CH} 50$, were obtained at mild reaction conditions, i.e., the reductive amination step was performed at low temperature, $\mathrm{pH} 5.0$ and the methylation step at room temperature, we considered that polydispersity of the polymers were kept under limited variation. The composition of chitosan intermediates and synthesized derivatives are summarized in Table 1. Derivatives mostly differentiate by the dimethylated and trimethylated contents as shown in Table 1 and Fig. 1.
Table 1

Physico-chemical properties of chitosan derivatives. \% GTM, \% GDM and \% GMM are the estimated contents of trimethylated, dimethylated and monomethylated units. \% DD stands for the content of dodecyl groups.

\begin{tabular}{llllll}
\hline Polymer & \% GMM & \% GDM & \% GTM & \% $\mathrm{NH}_{2}$ & $\%$ DD \\
\hline MeCH2 & 15.3 & 53.3 & 8.2 & 23.2 & - \\
CHDD20 & - & - & - & 77.9 & 20.1 \\
CH30 & - & 52.9 & 27.0 & - & 20.1 \\
CH50 & - & 27.6 & 49.3 & 3.0 & 20.1 \\
\hline
\end{tabular}

\subsection{Amphiphilic properties}

The interaction of amphiphilic polycations with cell membranes has been shown to depend on their hydrophilic/hydrophobic balance providing higher antimicrobial activities by the appropriated adjustment. This intrinsic property might strength the interaction with the cell membrane and could also introduce intra- and intermolecular interactions that affect antimicrobial activity. Derivatives of chitosan may aggregate as a result of intra- and intermolecular association. At $\mathrm{pH}$ around 5.5 and lower, derivatives are positively charged, and it is expected that self-association is driven by the hydrophobic effect. The $\mathrm{I}_{1} /$ $\mathrm{I}_{3}$ ratio of the fluorescence vibronic bands of pyrene report the onset of aggregation of polydisperse samples (Philippova et al., 2001), and allows the estimation of the critical aggregation concentration values (CACs). They were graphically estimated, as shown in Fig. 2, from the plots of $I_{1} / I_{3}$ in the presence of increasing concentrations of the derivatives, which show clear breaks due to self-association. For example, CH30 and $\mathrm{CH} 50$ exhibit a steep decrease in the $\mathrm{I}_{1} / \mathrm{I}_{3}$ ratios at $4.5 \times 10^{-3}$ and $31 \times 10^{-3} \mathrm{~g} \mathrm{~L}^{-1}$, respectively, while for CH2 the CAC under the same conditions is $57 \mathrm{~g} \mathrm{~L}^{-1}$ (Table 2). This illustrates how differently the hydrophobic effect of dodecyl groups overcomes electrostatic repulsion between positively charged groups, leading to the formation of intra- and/or intermolecular aggregates at these concentrations.

When concentrations of chitosan and derivatives are above the respective CAC values the interaction with cells and lipid bilayers may be affected by aggregated forms being less available as they were in solution (Kulikov et al., 2016).

\subsection{Bio-assays}

The antimicrobial activity of the derivatives $\mathrm{CH} 30$ and $\mathrm{CH} 50$ was determined in comparison to their parent compounds, $\mathrm{CH} 2$ and CHDD20, and a quaternized non-hydrophobic derivative, $\mathrm{MeCH} 2$, against Gram-negative (E. coli) and Gram-positive (S. aureus), which are representative of the most clinically important bacteria (Fig. 3). We

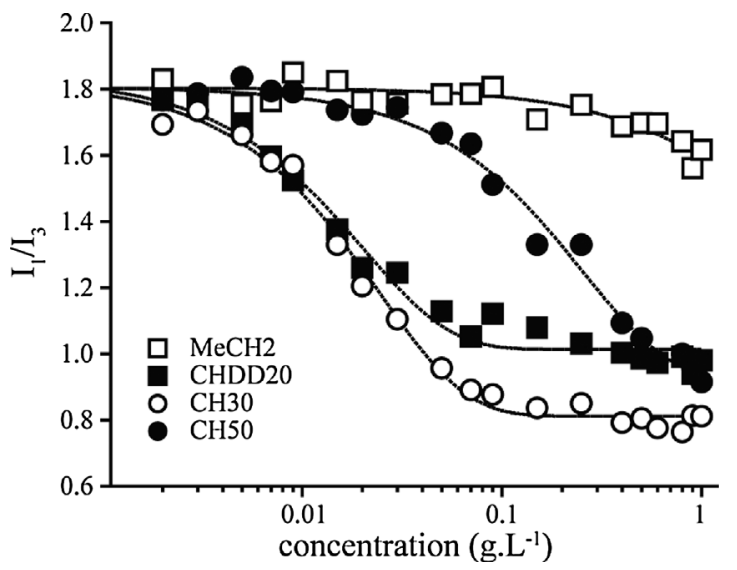

Fig. 2. Fluorometric CAC determination of derivatives through $I_{1} / I_{3}$ ratio of the probe pyrene, at $\mathrm{pH} 5.5$. 
$\mathrm{CHDD} 2 \mathrm{M} \mathrm{MeCH} 2 \mathrm{C}^{2} 30 \bullet \mathrm{CH} 50$
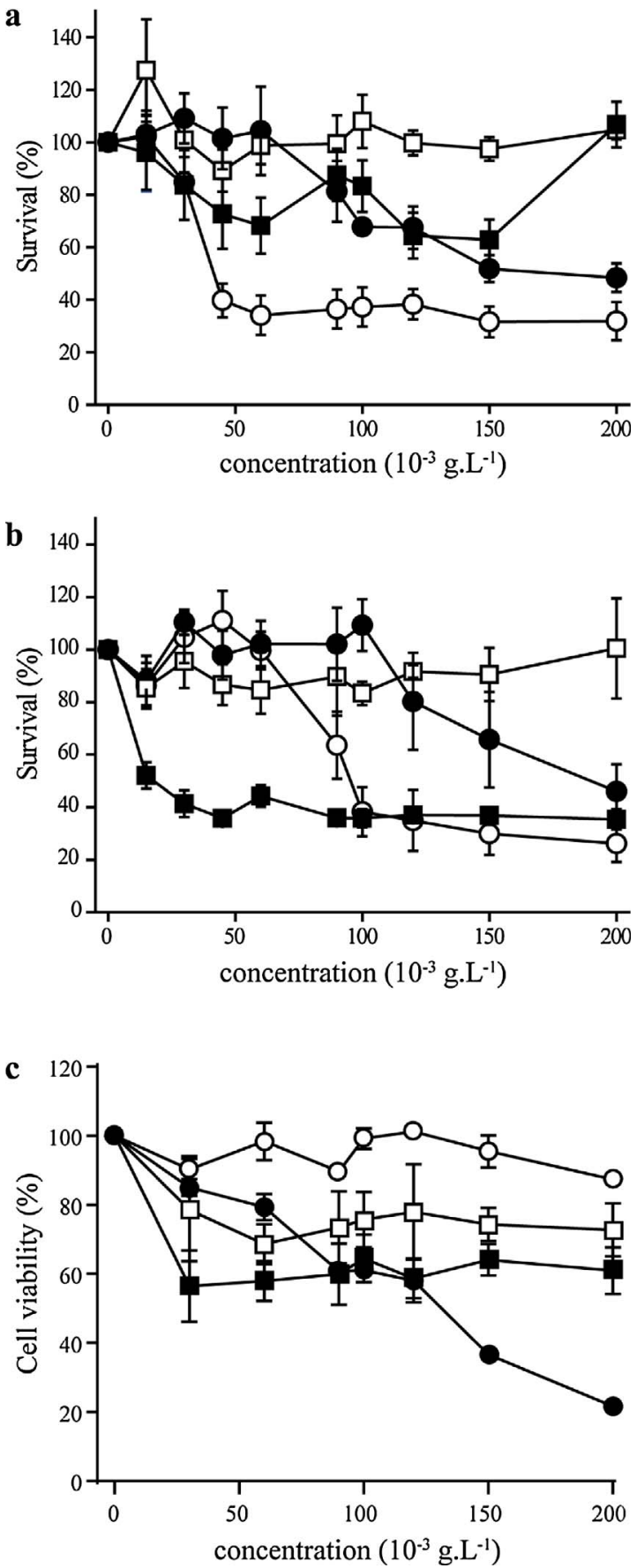

Fig. 3. Effect of chitosan derivatives concentration on the survival curves for $E$. coli (a) and $S$. aureus (b), and on the viability of human cervical carcinoma cells (c). Bacteria and cells were incubated with different concentrations of chitosan derivatives for $3 \mathrm{~h}$ and $24 \mathrm{~h}$, respectively. The survival rates were determined by the optical density in $600 \mathrm{~nm}$ (OD 600 ) and the cell viability was assessed by MTT reduction.

observed that $\mathrm{CH} 2$ (Fig. SI3a) and MeCH2 do not exhibit antimicrobial activity at any tested concentration, while the hydrophobic functionalized derivative, CHDD20, is as active as $\mathrm{CH} 30$ and $\mathrm{CH} 50$ just against $S$. aureus. However, when considering concentrations below $100 \times 10^{-3} \mathrm{~g} \mathrm{~L}^{-1}$, CHDD20 is more active than $\mathrm{CH} 30$ and $\mathrm{CH} 50$ against $S$. aureus, while against $E$. coli, $\mathrm{CH} 30$ is the most active. Nevertheless, none of the compounds totally eradicated bacteria, showing the minimum survival rate of $20 \%$ for $E$. coli. We must emphasize that the contact time of $3 \mathrm{~h}$ is longer than previously determined as required for significant bacterial cell wall permeability (Naberezhnykh, Bakholdina, Gorbach, \& Solov'eva, 2009). Also, the possible influence of iodide counter-ions was investigated along the experiments with the chitosan compounds. The control experiments show that at the maximum concentration of $4 \times 10^{-3} \mathrm{~g} \mathrm{~L}^{-1}$, it presents very limited influence on cell viability or survival (Fig. SI3b). These findings demonstrated that hydrophobic character and the presence of cationic groups are equally important for the development of a broad spectrum compound and that additional efforts are required in the development of chitosan derivatives with optimum antibacterial properties. In this sense, investigating the possible forms of chitosan derivatives interactions with lipid bilayers could positively contribute to the design of improved compounds.

The cytotoxic activity of chitosan derivatives toward human cervical carcinoma cells was assessed by the MTT assay. Fig. $3 \mathrm{c}$ shows that $\mathrm{MeCH} 2$ and $\mathrm{CH} 30$ do not exhibit cytotoxicity at $200 \times 10^{-3} \mathrm{~g} \mathrm{~L}^{-1}$. While $\mathrm{CH} 2$ (Fig. SI3a) and MeCH2 show small activity at half this concentration, CH2DD20 reduces cell viability to $60 \%$ at concentrations above $25 \times 10^{-3} \mathrm{~g} \mathrm{~L}^{-1}$. Just CH50 shows significant cytotoxicity, reducing the formazan production in a concentration-dependent manner.

The correlation between antimicrobial, cytotoxicity and physicochemical features as shown in Table 2 indicates that (1) the cationic charge is important for bioactivity; (2) but, the hydrophobicity conferred by dodecylation is even more important; (3) cationic charge and hydrophobicity produce better compounds either as antimicrobials or as tumoricidal agents; (4) the balance between cationicity and hydrophobicity obtained in $\mathrm{CH} 30$ is more suitable for the antimicrobial activity while that balance obtained in $\mathrm{CH} 50$ is better for the tumoricidal activity. Considering the CAC values, the concentration range in which the antimicrobial and cytotoxic activities of chitosan and derivatives were obtained include those where aggregated forms would be found in solution. This means that chitosan derivatives start exerting activities in their respective aggregated forms.

\subsection{Interactions with membrane models}

It has been demonstrated that chitosan is active at the cell surface of bacteria and leads to permeabilization. Also, it has been demonstrated that electrostatic and non-electrostatic interactions are important for the antimicrobial activity (Verlee et al., 2017). Thus, it seems relevant to investigate the activity of chitosan and its derivatives on model membranes to understand their mechanisms of action.

\subsubsection{Lytic activity}

Investigating the lytic activity of our compounds will indicate if they can target the cell membrane, permeabilize it and compromise its barrier properties. $\mathrm{CH} 30$ and $\mathrm{CH} 50$ are lytic compounds at low concentrations towards LUVs made of PC and PC/PG (70:30 mol\%, named PCPG), while the lytic activity is moderate towards LUVs made of PC/ PS/Chol (60:20:20 mol\%, named PCPSChol), and PG/CL (50:50 mol\%, named PGCL) (Fig. 4). In relation to the precursor CHDD20, CH30 and CH50 exhibit much intense activity, except on PGCL, where an

Table 2

Physicochemical features and bioactivity of chitosan and derivatives. \% GTM is the estimated contents of trimethylated units or charged units. CAC is the critical aggregation concentration. \% survival and \% cell viability as obtained at $150 \times 10^{-3} \mathrm{~g} \mathrm{~L}^{-1}$.

\begin{tabular}{c|ccccc}
\hline Polymer & $\begin{array}{c}\text { \% } \\
\text { GTM }\end{array}$ & $\begin{array}{c}\text { CAC } \\
\left(\times \mathbf{1 0}^{-\mathbf{3}} \mathbf{\text { g.L }} \mathbf{-}^{\mathbf{1}}\right)\end{array}$ & $\begin{array}{c}\boldsymbol{E} \text {. coli } \\
\text { \% survival }\end{array}$ & $\begin{array}{c}\text { S. aureus } \\
\text { \% survival }\end{array}$ & $\begin{array}{c}\text { HeLa cells } \\
\text { \% cell viability }\end{array}$ \\
\hline $\mathrm{CH} 2$ & - & 57 & $144 \pm 12$ & $176 \pm 4$ & $77 \pm 3$ \\
MeCH2 & 8.2 & 77 & $97 \pm 4$ & $91 \pm 10$ & $74 \pm 5$ \\
CHDD20 & - & 3.5 & $63 \pm 8$ & $37 \pm 2$ & $64 \pm 5$ \\
CH30 & 27.0 & 4.5 & $32 \pm 6$ & $30 \pm 8$ & $96 \pm 5$ \\
CH50 & 49.3 & 31 & $51 \pm 4$ & $66 \pm 18$ & $37 \pm 2$ \\
\hline
\end{tabular}

Highlighted in grey are the best results obtained by the derivatives. 

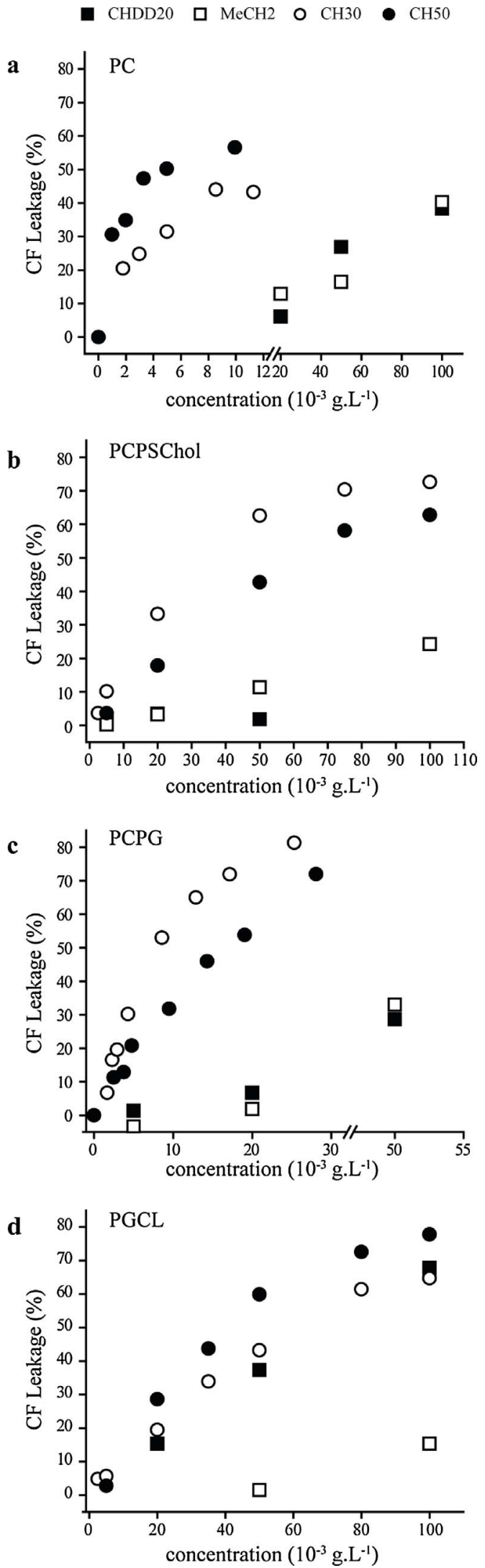

Fig. 4. The permeabilizing effect of chitosan derivatives in different membrane mimetic systems as determined from the dye leakage of the entrapped CF. $100 \%$ leakage is that induced by Triton. Dose-response curves obtained after $10 \mathrm{~min}$ contact time, at $25^{\circ} \mathrm{C}$ with LUVs made of (a) PC, (b) PC/PS/Chol (60:20:20 mol\%), (c) PC/PG (70:30 mol\%), (d) PG/ CL (50:50 mol\%). equivalent activity was observed. For MeCH2 limited lytic activity was detected at concentrations above $50 \times 10^{-3} \mathrm{~g} \mathrm{~L}^{-1}$, while for $\mathrm{CH} 2$ (Fig. SI4) some activity was found in PC and PGCL vesicles. CH30 and CH50 exhibit similar kinetic profile tending to a plateau after 5 min contact. Nevertheless, $100 \%$ leakage is not achieved for any derivative. Strong flocculation occurs in some cases above 5 min contact time with $\mathrm{CH} 30$ around $25 \times 10^{-3} \mathrm{~g} \mathrm{~L}^{-1}$ and with CH50 above $14 \times 10^{-3} \mathrm{~g} \mathrm{~L}^{-1}$ in PCPG LUV. The dose-response curves indicate that the interaction of these derivatives is not cooperative; the calculated Hill coefficients are close to 1 . CH30 exhibits more intense lytic activity than $\mathrm{CH} 50$ on the anionic vesicles PCPG and PCPSChol and slightly less intense activity on the zwitterionic PC. These observations suggest a more selective performance of $\mathrm{CH} 30$, probably as a result of a more suitable hydrophobic/hydrophilic balance. Although CH50 shows more intense lytic activity than CH30 on PGCL, both derivatives and precursors are much less efficient in this vesicle that mimics Gram-positive bacteria membranes. Bilayers containing cholesterol and cardiolipin are known for being less fluid than those where these phospholipids are absent (dos Santos Cabrera et al., 2012). Moreover, chitosan activity was reported to be negatively influenced by cell membrane fluidity in experiments with resistant fungi (Verlee et al., 2017). This could be the reason for the lytic activity appearing quite similar in PGCL for CH50, CH30 and CHDD20, while in PCPG the derivatives are significantly more efficient.

\subsubsection{Zeta potential measurements}

Once that our compounds are lytic to vesicles mimicking the membranes of bacteria and tumors, zeta potential measurements will indicate the importance of the electrostatic attraction and confirm that binding occurs. For zeta potential measurements the permanently charged compounds, $\mathrm{CH} 30$, $\mathrm{CH} 50$ and $\mathrm{MeCH} 2$, were considered. They neutralize membrane charges by binding to the more fluid membranes, PCPG and PC, with a significant preferential interaction with the anionic one. Fig. 5 shows that increasing the concentration of chitosan derivatives increase the initial electro-kinetic potential $\left(\zeta_{0}\right)$ as a consequence of the polycation binding to the vesicles surface and neutralization of charges. On PGCL, MeCH2 exhibits a more pronounced charge neutralization effect, while in PCPSChol, CH50 is the more efficient, in good agreement with its superior effect in HeLa cells. CH30 shows poor binding to these less fluid bilayers. Their respective isotherms, as well as the dose-response curves of the lytic activity, suggest that the partition of these chitosan derivatives depends on the fluidity of vesicle compositions. This was confirmed when the interaction of CH30 and CH50 was investigated on PC/PS/Ergosterol (40:40:20 mol \%) LUVs. In this environment that mimics $C$. albicans membranes and in PCPG, CH30 and CH50 performed similarly (Fig. SI5). CH50 is more efficient in promoting charge neutralization than $\mathrm{CH} 30$, as could be expected from its higher cationic character, except on PGCL. Although deprived of biological and lytic activities, MeCH2 shows efficient charge neutralization in the anionic vesicles tested, and shows potential reversal in PCPG and PCPSChol. For CH30, the potential reversal occurs around $23 \times 10^{-3} \mathrm{~g} \mathrm{~L}^{-1}$ in PCPG. At this concentration flocculation was observed in the leakage experiments. With $\mathrm{CH} 50$ the isotherm obtained in PCPG shows an abrupt increase in zeta potential at the concentration around $5 \times 10^{-3} \mathrm{~g} \mathrm{~L}^{-1}$, and the potential reversal occurs around $8 \times 10^{-3} \mathrm{~g} \mathrm{~L}^{-1}$. Also, flocculation was observed. Most isotherms tend to a plateau, suggesting that compounds are aggregating. The aggregation is supported by vesicle size measurements (Fig. 6).

Whereas results of the bioassays clear indicate that $\mathrm{CH} 30$ would be more efficient as an antimicrobial and CH50 more efficient as an antitumoral, and also that $\mathrm{CH} 30$ would be equally effective against Gramnegative and Gram-positive bacteria, results using mimetic membranes does not discriminate their action in the same way. The mechanism of action of $\mathrm{CH} 30$ and $\mathrm{CH} 50$ seems to be directed by electrostatic interactions. CH30 with lower cationic character is more lytic towards PCPG and PCPSChol, the less anionic lipid bilayers, while CH50 is more lytic 

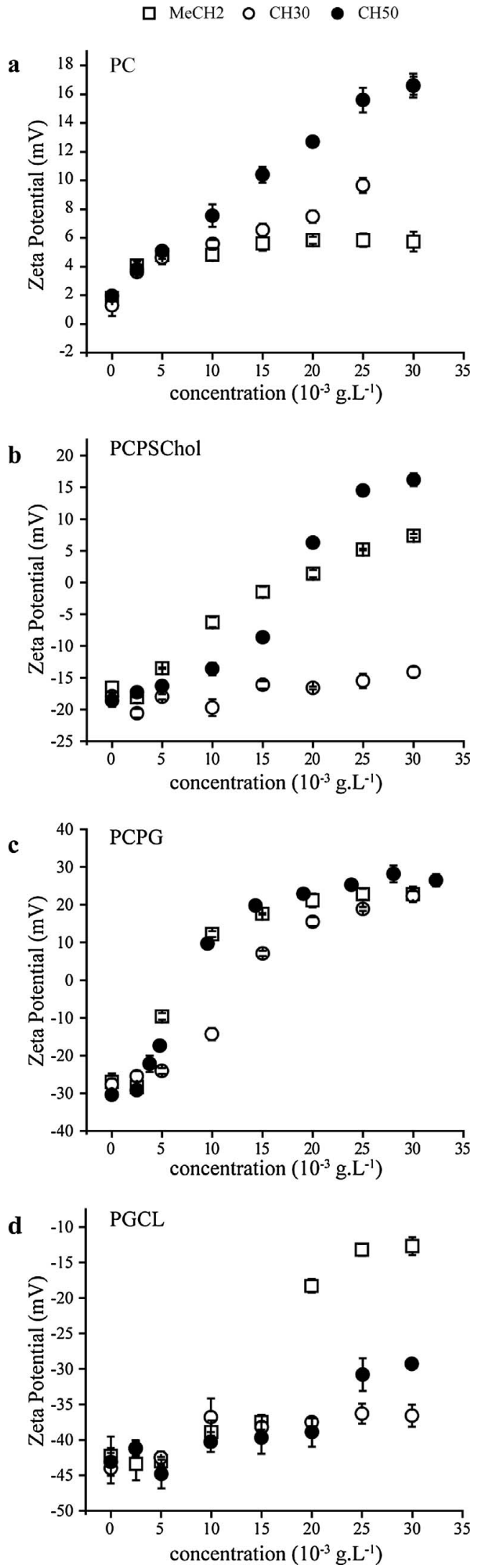

Fig. 5. Zeta potential isotherms obtained with LUVs after $30 \mathrm{~min}$ equilibration time, at $\mathrm{pH} 5.5$ and $25^{\circ} \mathrm{C}$. Zeta potential for LUVs in the absence of chitosan derivatives ( $\left.\zeta_{0}, \mathrm{mV}\right)$ are: (a) PC, $+1.2 \pm 0.2$; (b) PCPSChol, $-18 \pm 1$; (c) PCPG, $-29 \pm 2 \mathrm{mV}$; (d) PGCL $-43 \pm 2$.
$\begin{array}{llll}\mathrm{CHDD} 20 & \mathrm{MeCH} 2 & \mathrm{CH} 30 & \mathrm{CH} 50\end{array}$
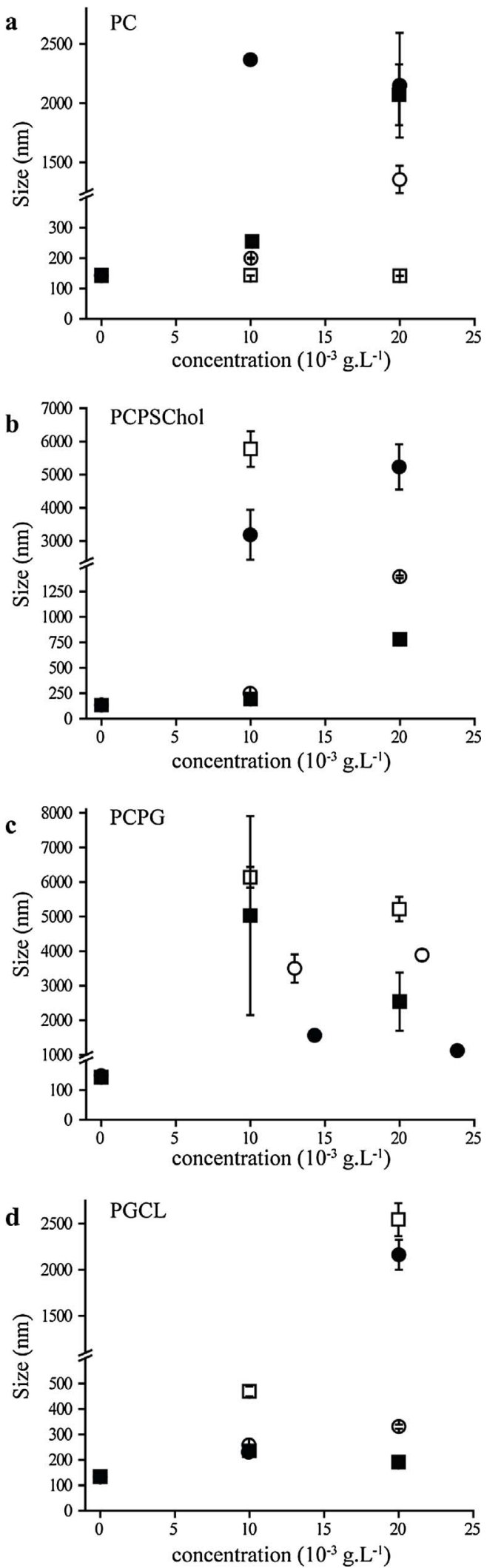

Fig. 6. Vesicles size determinations obtained with LUVs after 30 min equilibration time, at pH 5.5 and $25^{\circ} \mathrm{C}$. LUVs size in the absence of chitosan derivatives (in nm): (a) PC, $143 \pm 2$; (b) PCPSChol, $133 \pm 1$; (c) PCPG, $148 \pm 2$; (d) PGCL, $133 \pm 1$ 
towards PGCL. Nevertheless, experiments with lipid vesicles were very helpful to demonstrate that derivatives endowed with hydrophobicity and net charges, as $\mathrm{CH} 30$ and $\mathrm{CH} 50$, were the most promising candidates for further developments as antimicrobials.

\subsubsection{Vesicle size determinations}

The size variations of vesicles indicate the extent of aggregation that our compounds could induce as a consequence of intense electrostatic attractions or hydrophobic interactions. Fig. 6 shows changes in vesicles size induced by the increasing concentrations of chitosan derivatives. In the presence of PC vesicles, they show significant size increase, except for $\mathrm{MeCH} 2$. Although CHDD20 induce significant size increase at $20 \times 10^{-3} \mathrm{~g} \mathrm{~L}^{-1}$, poor lytic activity was observed in PC. Thus, these data could be correlated to the lack of (or limited) strong interactions; electrostatic in the case of CHDD20 and non-electrostatic for MeCH2. Derivatives $\mathrm{CH} 30$ and $\mathrm{CH} 50$ are endowed with both types of interactions.

In the presence of PCPSChol LUVs, MeCH2 induce the highest size increase that may denote vesicles aggregation, at $10 \times 10^{-3} \mathrm{~g} \mathrm{~L}^{-1}$. $\mathrm{MeCH} 2$ is followed by CH50, while $\mathrm{CH} 30$ and CHDD20 show moderate size increase at $20 \times 10^{-3} \mathrm{~g} \mathrm{~L}^{-1}$. Nevertheless, just CH50 and CH30 show significant lytic activity at $50 \times 10^{-3} \mathrm{~g} \mathrm{~L}^{-1}$ in this model membrane. And only CH50 showed cytotoxicity towards HeLa cells. The CAC of CH30 and CHDD20 are below $20 \times 10^{-3} \mathrm{~g} \mathrm{~L}^{-1}$. Taken together these data suggest that a) $\mathrm{CH} 30$ activity is impaired by the lower fluidity of cholesterol-containing bilayers, and by its aggregated state in solution that hinders its binding, as seen in the zeta potential measurements; b) CH50 activity is increased by the higher content of positively charged groups that enhances binding, and by a higher CAC value; and c) the cationic $\mathrm{MeCH} 2$ strongly binds and aggregates vesicles but the lack of hydrophobic character impairs its activity.

In relation to the bacterial model membranes, chitosan derivatives induce intense size increase, denoting vesicles aggregation, in PCPG, around $10 \times 10^{-3} \mathrm{~g} \mathrm{~L}^{-1}$ concentration. Limited aggregation was observed in PGCL. This could be attributed to three oppositely acting conditions in PCPG and PGCL: a) the availability of plenty of anionic groups (PGCL) to neutralize chitosan and derivatives positively charged groups; b) strong remaining repulsion between LUVs (PGCL); and c) reduced fluidity of PGCL LUVs.

\section{Discussion}

There are some recognized advantages when antimicrobials target the membrane of cells, as their highly preserved features and essentiality among several bacterial species throughout evolution, their ability to act on the membranes of dormant bacteria and on biofilms, and their decreased probability of resistance development (Mingeot-Leclercq \& Décout, 2016; Zasloff, 2002). Biophysical parameters of these membranes rule the activity of membrane-active compounds as the amphiphilic character, fluidity, intrinsic curvature and clustering of lipids (Mingeot-Leclercq \& Décout, 2016). Thus, to achieve an optimized interaction, the antimicrobial compounds must be endowed with a specific balance between the hydrophobic and hydrophilic character, which includes a significant content of cationic charges, and an accurate evaluation of the molecular weight (Mingeot-Leclercq \& Décout, 2016; Verlee et al., 2017).

Amphiphilic antibacterial aminoglycosides have been developed from an old class of drugs, the aminoglycosides, as an alternative to overcome the difficulties imposed by the emergence of resistant bacteria. This new class, which includes chitosan and derivatives, may be made to target the anionic lipid bilayer of bacteria (Mingeot-Leclercq \& Décout, 2016; Verlee et al., 2017). The interaction starts with the electrostatic attraction between protonated amino groups of chitosan and derivatives and the negatively charged components of the bacterial cell surface. This surface may become decorated with chitosan and be permeabilized leaking the intracellular content (Naberezhnykh et al.,
2009; Verlee et al., 2017; Wu, Long, Xiao, \& Dong, 2016). The results of the present work also point out to this mechanism of action, which has been often associated with antimicrobial peptides. This class of substances has called the attention of researchers for over two decades because its mechanism of action does not require specific receptors, and thus also presents a different strategy to overcome the development of resistance towards antibiotic therapy.

It has been reported that chitosan with approximately the same characteristics of $\mathrm{Mw}$ and deacetylation degree as our $\mathrm{CH} 2$ exhibits MIC around $200 \times 10^{-3} \mathrm{~g} \mathrm{~L}^{-1}$ for $S$. aureus and $E$. coli at $\mathrm{pH} 6.9$ (Kulikov et al., 2016), however, in the present work we did not find antimicrobial activity for $\mathrm{CH} 2$ even at $500 \times 10^{-3} \mathrm{~g} \mathrm{~L}^{-1}$. It was also the case with $\mathrm{MeCH} 2$, while the literature reports that fully quaternized chitosan has higher antibacterial activity than the parent chitosan (Wu et al., 2016). Nevertheless, $\mathrm{CH} 30$ and $\mathrm{CH} 50$ exhibited antibacterial activity at comparable levels toward Gram-negative E. coli and Grampositive $S$. aureus, mimicked respectively by PCPG and PGCL. Accordingly they presented lytic activity in these lipid vesicles, although being more intense in PCPG. CH50 also exhibited cytotoxic activity towards Hela cells. This set of activities was not displayed by their precursors, although the hydrophobic CHDD20 showed similar antibacterial activity towards $S$. aureus. Thus, it justifies and encourages studies involving modifications of natural chitosan that focus on fine-tuning hydrophobic and electrostatic interactions.

As pointed out for chitosan-resistant fungi (Verlee et al., 2017), the differences found in the interaction of the presently developed derivatives with lipid bilayers also evidence characteristics already described for chitosan, as the impairment effect of membrane fluidity on the membrane-related activity. Binding and lytic activity of $\mathrm{CH} 30$ and CH50 were reduced when bilayers contained cholesterol or cardiolipin, lipids that strongly influence membrane packing and fluidity. Also, for Gram-positive bacterial membranes, which contain cardiolipin, it was demonstrated that a mutant lacking the outer layer rich in teichoic acids had impaired chitosan activity (Verlee et al., 2017). Moreover, exposure to chitosan caused important morphological changes in the cell wall (Kulikov et al., 2016). These findings evidence the importance of strong electrostatic interactions as a way to overcome the membrane reduced fluidity. Although deprived of antibacterial activity, our precursor, $\mathrm{MeCH} 2$, with a high CAC value, showed increased binding on PGCL bilayers probably as a result of the high availability of positively charged groups. For many antibacterial compounds, including chitosan, the antibacterial activity depends on solubility (Kulikov et al., 2016). For Gram-negative bacteria, studies demonstrated that chitosan disturbs the inner membrane and induces leakage. Accordingly, we found that on PCPG LUVs, binding of $\mathrm{CH} 30$, $\mathrm{CH} 50$ and $\mathrm{MeCH} 2$ are comparable; however, $\mathrm{MeCH} 2$ shows much reduced permeabilization and lacks activity toward E.coli (Verlee et al., 2017).

The literature is rich in relation to the antitumoral activity of chitosans, however in this field of application chitosan is mostly used as a carrier or nanoparticle. However, its appeal as a pH-responsive compound could equally be of interest to our compounds, considering that the mechanism where the target is the membrane could be verified. Cancer cells expose increased content of anionic PS in the outer leaflet of the cytoplasmic membrane, favoring electrostatic interactions (Zwaal et al., 2005) as in the case of antibacterial activity. Other appealing features of chitosan should be considered as its facilitated adsorption at the cancer cell membrane due to electrostatic interactions and to the presence of secondary and tertiary amino groups, and the abundant possibilities of hydrogen-bonding that enhances for longer the adhesive effect (Suarato, Li, \& Meng, 2016). From our set of compounds, CH50 was the only derivative endowed with significant activity toward HeLa cells. It has already been reported that chitosan may bind non-covalently with cholesterol (Verlee et al., 2017), suggesting the importance of other interactions besides the electrostatic. We also verified that the presence of cholesterol in the lipid bilayers, turning them less fluid, reduced the binding and lytic activity of the derivatives on the model 

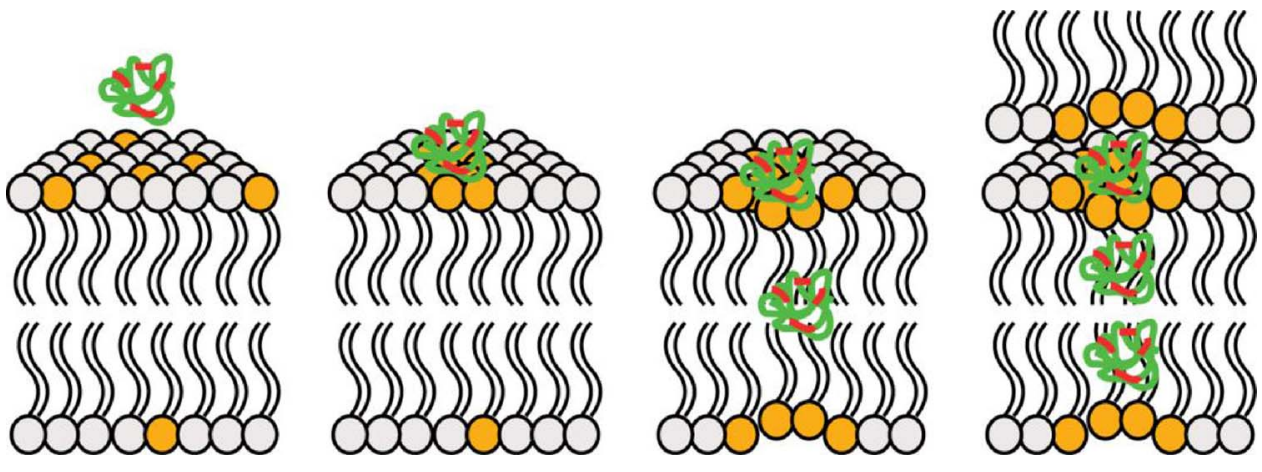

Fig. 7. Model of the lytic activity of chitosan derivatives. The electrostatic attraction between quaternary chitosans, acting as aggregates, binds them to the vesicles surface, clusters anionic phospholipids, disturbs the lipid packing, leaks vesicles' content, attracts or extracts the anionic phospholipids from the opposite layer and also attracts and packs other vesicles as denoted by the size increase. The clustering of vesicles hinders the total leakage of vesicles' content. membrane PCPSChol, despite the presence of $30 \%$ anionic PS. CH50 is the derivative that most strongly binds and neutralizes the charges of PCPSChol, although it is not the most efficient as a membranolytic compound in this vesicle.

The kinetics of the lytic activity observed for $\mathrm{CH} 30$ and $\mathrm{CH} 50$ resembles those found for antimicrobial peptides, however the dose-response curves are different: lytic antimicrobial peptides usually exhibit a sigmoid shaped curve and a cooperative behavior (Cabrera et al., 2014; dos Santos Cabrera et al., 2009), while the present chitosan derivatives do not. The stronger effect of $\mathrm{CH} 50$ than that of $\mathrm{CH} 30$ on PC vesicles is also compatible with the effect of highly charged cationic peptides. For those peptides, the increased charge abolishes the selective behavior towards anionic bilayers (Dathe, Nikolenko, Meyer, Beyermann, \& Bienert, 2001). Significant similarities with lytic peptides behavior are also found in the effects of the present chitosan derivatives on the zeta potential isotherms, except for the potential reversal observed at lower concentration. Aggregated particles probably made of chitosan and phospholipids were denoted by the size increase and also visually observed. This finding and the fact that our chitosan derivatives do not reach $100 \%$ leakage of vesicles content oppose to the features generally attributed to the detergent-like mechanism (Henzler Wildman, Lee, \& Ramamoorthy, 2003). This mode of action was recently attributed to nanocapsules of chitosan. ${ }^{52}$ However, the features exhibited by our derivatives suggest that their mode of action could be attributed to the formation of chitosan/phospholipids aggregates and is comparable to the charge cluster mechanism, which was recently ascribed to peptides with high positive charge density (Epand, Maloy, Ramamoorthy, \& Epand, 2010). Another characteristic of these peptides that promote charge cluster is the fact that the ratio between MICs in S. aureus to E. coli is above 1, which we also found in our chitosan compounds. A kind of charge clustering was also proposed for supported chitosan derivatives with antimicrobial activity (Li et al., 2011). Fig. 7 summarizes the sequence of events that were observed and correlated with this mechanism.

\section{Conclusions}

CH30 and CH50 differentiate by the number of charged groups in the polymer chain, which is higher in CH50. Both derivatives exhibit antimicrobial and cytotoxic activities, which are increased in relation to the precursor compounds. The experiments with model membranes evidenced that these amphiphilic chitosan derivatives show strong affinity for phospholipid bilayers, capable of inducing significant lytic activity at concentrations around $10 \times 10^{-3} \mathrm{~g} \mathrm{~L}^{-1}$, when vesicles composition was of higher fluidity, or around $40 \times 10^{-3} \mathrm{~g} \mathrm{~L}^{-1}$, for vesicles containing cardiolipin or cholesterol. Although the mechanism of the antimicrobial activity of chitosan and derivatives are not well understood, the leakage of intracellular compounds has already been observed (Fernandes et al., 2014; Rabea et al., 2003). One of the proposed mechanisms associates the electrostatic interaction between cationic groups of chitosan and the anionic groups of the membrane that induce the leakage of the cell contents (Fernandes et al., 2014; Li et al., 2011). This interaction that starts from electrostatic attraction and targets the phospholipid matrix of cell membranes has been often associated to antimicrobial peptides and represents a strategy to overcome the mechanisms of bacterial resistance. The results of the present work point out to the advantages of parallel investigation of chitosan derivatives effects on the lipid bilayer of cell membranes and suggest that besides improving the hydrophobic/hydrophilic balance of compounds, modifications that increase CAC and reduce aggregated contents could improve efficiency.

\section{Acknowledgements}

This work was supported by grants from Fundação de Amparo à Pesquisa do Estado de São Paulo (FAPESP), Brasil, to, M.J.T. (2009/ 11707-2; 2012/03619-9); M.A.-M. (2012/02065-0); M.P.D.S.C. (2010/ 11823-0; 2012/24259-0; 2014/08372-7).

The authors are grateful to Dr. Antonio Carlos Pignatari and Dr. Magnus Régios da Silva (Federal University of São Paulo) for kindly providing S. aureus (ATCC 25923) and HeLa cells, respectively.

\section{Appendix A. Supplementary data}

Supplementary data associated with this article can be found, in the online version, at https://doi.org/10.1016/j.carbpol.2017.12.011.

\section{References}

Bautista-Baños, S., Hernández-Lauzardo, A. N., Velázquez-del Valle, M. G., HernándezLópez, M., Ait Barka, E., Bosquez-Molina, E., \& Wilson, C. L. (2006). Chitosan as a potential natural compound to control pre and postharvest diseases of horticultural commodities. Crop Protection, 25(2), 108-118. http://dx.doi.org/10.1016/j.cropro. 2005.03.010.

Benediktsdóttir, B. E., Gudjónsson, T., Baldursson, Ó., \& Másson, M. (2014). N-alkylation of highly quaternized chitosan derivatives affects the paracellular permeation enhancement in bronchial epithelia in vitro. European Journal of Pharmaceutics and Biopharmaceutics, 86(1), 55-63. http://dx.doi.org/10.1016/j.ejpb.2013.04.002.

Berridge, M. V., \& Tan, A. S. (1993). Characterization of the cellular reduction of 3-(4,5dimethylthiazol-2-yl)-2,5-diphenyltetrazolium bromide (MTT): Subcellular localization, substrate dependence, and involvement of mitochondrial electron transport in MTT reduction. Archives of Biochemistry and Biophysics, 303(2), 474-482. http://dx. doi.org/10.1006/abbi.1993.1311.

Cabrera, M. P., Baldissera, G., Silva-Gonçalves, L. da, C., De Souza, B. M., Riske, K. A., Palma, M. S., ... Arcisio-Miranda, M. (2014). Combining experimental evidence and molecular dynamic simulations to understand the mechanism of action of the antimicrobial octapeptide jelleine-I. Biochemistry, 53(29), 4857-4868. http://dx.doi.org/ 10.1021/bi5003585.

Dathe, M., Nikolenko, H., Meyer, J., Beyermann, M., \& Bienert, M. (2001). Optimization of the antimicrobial activity of magainin peptides by modification of charge. FEBS Letters, 501(2-3), 146-150.

de Oliveira Pedro, R., Takaki, M., Gorayeb, T. C. C., Del Bianchi, V. L., Thomeo, J. C., Tiera, M. J., \& de Oliveira Tiera, V. A. (2013). Synthesis, characterization and antifungal activity of quaternary derivatives of chitosan on Aspergillus flavus. Microbiological Research, 168(1), 50-55. http://dx.doi.org/10.1016/j.micres.2012. 06.006.

de Oliveira Tiera, V. A., Winnik, F. M., \& Tiera, M. J. (2010). Interaction of amphiphilic derivatives of chitosan with DPPC (1,2-dipalmitoyl-sn-glycero-3-phosphocholine). Journal of Thermal Analysis and Calorimetry, 100(1), 309-313. http://dx.doi.org/10. 1007/s10973-009-0375-y. 
Desbrières, J., Martinez, C., \& Rinaudo, M. (1996). Hydrophobic derivatives of chitosan: Characterization and rheological behaviour. International Journal of Biological Macromolecules, 19(1), 21-28 [Retrieved from http://www.ncbi.nlm.nih.gov/ pubmed/8782715]

Dobrzyńska, I., Szachowicz-Petelska, B., Sulkowski, S., \& Figaszewski, Z. (2005). Changes in electric charge and phospholipids composition in human colorectal cancer cells. Molecular and Cellular Biochemistry, 276(1-2), 113-119. http://dx.doi.org/10.1007/ s11010-005-3557-3.

dos Santos Cabrera, M. P., Arcisio-Miranda, M., da Costa, L. C., de Souza, B. M., Broggio Costa, S. T., Palma, M. S., ... Procopio, J. (2009). Interactions of mast cell degranulating peptides with model membranes: A comparative biophysical study. Archives of Biochemistry and Biophysics, 486(1), 1-11. http://dx.doi.org/10.1016/j. abb.2009.03.009.

dos Santos Cabrera, M. P., Arcisio-Miranda, M., Gorjão, R., Leite, N. B., De Souza, B. M., Curi, R., ... Palma, M. S. (2012). Influence of the bilayer composition on the binding and membrane disrupting effect of Polybia-MP1, an antimicrobial mastoparan peptide with leukemic T-lymphocyte cell selectivity. Biochemistry, 51(24), 4898-4908. http://dx.doi.org/10.1021/bi201608d.

Epand, R. F., Maloy, W. L., Ramamoorthy, A., \& Epand, R. M. (2010). Probing the charge cluster mechanism in amphipathic helical cationic antimicrobial peptides. Biochemistry, 49(19), 4076-4084. http://dx.doi.org/10.1021/bi100378m.

Fang, N., Chan, V., Mao, H. Q., \& Leong, K. W. (2001). Interactions of phospholipid bi layer with chitosan: Effect of molecular weight and pH. Biomacromolecules, 2(4), 1161-1168.

Fernandes, M. M., Francesko, A., Torrent-Burgués, J., Carrión-Fité, F. J., Heinze, T., \& Tzanov, T. (2014). Sonochemically processed cationic nanocapsules: Efficient antimicrobials with membrane disturbing capacity. Biomacromolecules, 15(4), 1365-1374. http://dx.doi.org/10.1021/bm4018947.

Fernandez-Megia, E., Novoa-Carballal, R., Quiñoá, E., \& Riguera, R. (2007). Conjugation of bioactive ligands to PEG-grafted chitosan at the distal end of PEG. Biomacromolecules, 8(3), 833-842. http://dx.doi.org/10.1021/bm060889x.

González-Aguilar, G. A., Valenzuela-Soto, E., Lizardi-Mendoza, J., Goycoolea, F., Martínez-Téllez, M. A., Villegas-Ochoa, M. A., ... Ayala-Zavala, J. F. (2009). Effect of chitosan coating in preventing deterioration and preserving the quality of fresh-cut papaya Maradol. Journal of the Science of Food and Agriculture, 89(1), 15-23. http:// dx.doi.org/10.1002/jsfa.3405.

Guo, Z., Xing, R., Liu, S., Zhong, Z., Ji, X., Wang, L., \& Li, P. (2008). The influence of molecular weight of quaternized chitosan on antifungal activity. Carbohydrate Polymers, 71(4), 694-697. http://dx.doi.org/10.1016/j.carbpol.2007.06.027.

Henzler Wildman, K. A., Lee, D.-K., \& Ramamoorthy, A. (2003). Mechanism of lipid bilayer disruption by the human antimicrobial peptide, LL-37. Biochemistry, 42(21), 6545-6558. http://dx.doi.org/10.1021/bi0273563.

Huo, M., Zhang, Y., Zhou, J., Zou, A., Yu, D., Wu, Y., ... Li, H. (2010). Synthesis and characterization of low-toxic amphiphilic chitosan derivatives and their application as micelle carrier for antitumor drug. International Journal of Pharmaceutics, 394(1-2), 162-173. http://dx.doi.org/10.1016/j.ijpharm.2010.05.001.

Jung, B.-O., Kim, C.-H., Choi, K.-S., Lee, Y. M., \& Kim, J.-J. (1999). Preparation of amphiphilic chitosan and their antimicrobial activities. Journal of Applied Polymer Science, 72(13), 1713-1719. http://dx.doi.org/10.1002/(SICI)1097-4628(19990624) 72:13《1713:AID-APP7》> 3.0.CO;2-T.

Kong, M., Chen, X. G., Xing, K., \& Park, H. J. (2010). Antimicrobial properties of chitosan and mode of action: A state of the art review. International Journal of Food Microbiology, 144(1), 51-63. http://dx.doi.org/10.1016/j.ijfoodmicro.2010.09.012.

Kulikov, S. N., Lisovskaya, S. A., Zelenikhin, P. V., Bezrodnykh, E. A., Shakirova, D. R., Blagodatskikh, I. V., \& Tikhonov, V. E. (2014). Antifungal activity of oligochitosans (short chain chitosans) against some Candida species and clinical isolates of Candida albicans: Molecular weight-activity relationship. European Journal of Medicinal Chemistry, 74, 169-178. http://dx.doi.org/10.1016/j.ejmech.2013.12.017.

Kulikov, S. N., Bayazitova, L. T., Tyupkina, O. F., Zelenikhin, P. V., Salnikova, M. M., Bezrodnykh, E. A., \& Tikhonov, V. E. (2016). Evaluation of a method for the determination of antibacterial activity of chitosan. Applied Biochemistry and Microbiology, 52(5), 502-507. http://dx.doi.org/10.1134/S0003683816050100.

Li, P., Poon, Y. F., Li, W., Zhu, H.-Y., Yeap, S. H., Cao, Y., ... Chan-Park, M. B. (2011). A polycationic antimicrobial and biocompatible hydrogel with microbe membrane suctioning ability. Nature Materials, 10(2), 149-156. http://dx.doi.org/10.1038/ nmat2915.

Lohner, K., \& Prenner, E. J. (1999). Differential scanning calorimetry and X-ray diffraction studies of the specificity of the interaction of antimicrobial peptides with membrane-mimetic systems. Biochimica et Biophysica Acta, 1462(1-2), 141-156.

Matsuzaki, K., Sugishita, K., Fujii, N., \& Miyajima, K. (1995). Molecular basis for membrane selectivity of an antimicrobial peptide, magainin 2. Biochemistry, 34(10), 3423-3429.

Mertins, O., \& Dimova, R. (2013). Insights on the interactions of chitosan with phospholipid vesicles. Part II: Membrane stiffening and pore formation. Langmuir, 29(47), 14552-14559. http://dx.doi.org/10.1021/la4032199.

Mertins, O., Sebben, M., Pohlmann, A. R., \& da Silveira, N. P. (2005). Production of soybean phosphatidylcholine-chitosan nanovesicles by reverse phase evaporation: A step by step study. Chemistry and Physics of Lipids, 138(1-2), 29-37. http://dx.doi. org/10.1016/j.chemphyslip.2005.07.004.

Mertins, O., Cardoso, M. B., Pohlmann, A. R., \& da Silveira, N. P. (2006). Structural evaluation of phospholipidic nanovesicles containing small amounts of chitosan. Journal of Nanoscience and Nanotechnology, 6(8), 2425-2431.

Mingeot-Leclercq, M.-P., \& Décout, J.-L. (2016). Bacterial lipid membranes as promising targets to fight antimicrobial resistance, molecular foundations and illustration through the renewal of aminoglycoside antibiotics and emergence of amphiphilic aminoglycosides. MedChemComm, 7(4), 586-611. http://dx.doi.org/10.1039/ C5MD00503E.

Naberezhnykh, G. A., Bakholdina, S. I., Gorbach, V. I., \& Solov'eva, T. F. (2009). New chitosan derivatives with potential antimicrobial activity. Russian Journal of Marine Biology, 35(6), 498-503. http://dx.doi.org/10.1134/S106307400906008X.

Philippova, O. E., Volkov, E. V., Sitnikova, N. L., Khokhlov, A. R., Desbrieres, J., \& Rinaudo, M. (2001). Two types of hydrophobic aggregates in aqueous solutions of chitosan and its hydrophobic derivative. Biomacromolecules, 2, 483-490. http://dx. doi.org/10.1021/BM005649A.

Quemeneur, F., Rinaudo, M., \& Pépin-Donat, B. (2008). Influence of polyelectrolyte chemical structure on their interaction with lipid membrane of zwitterionic liposomes. Biomacromolecules, 9(8), 2237-2243. http://dx.doi.org/10.1021/bm800400y.

Rúnarsson, Ö. V., Holappa, J., Nevalainen, T., Hjálmarsdóttir, M., Järvinen, T., Loftsson, T., ... Másson, M. (2007). Antibacterial activity of methylated chitosan and chitooligomer derivatives: Synthesis and structure activity relationships. European Polymer Journal, 43(6), 2660-2671. http://dx.doi.org/10.1016/j.eurpolymj.2007.03. 046.

Rúnarsson, Ö. V., Holappa, J., Jónsdóttir, S., Steinsson, H., \& Másson, M. (2008). Nselective one pot synthesis of highly N-substituted trimethyl chitosan (TMC). Carbohydrate Polymers, 74(3), 740-744. http://dx.doi.org/10.1016/j.carbpol.2008. 03.008 .

Rúnarsson, Ö. V., Holappa, J., Malainer, C., Steinsson, H., Hjálmarsdóttir, M., Nevalainen, T., \& Másson, M. (2010). Antibacterial activity of N-quaternary chitosan derivatives: Synthesis, characterization and structure activity relationship (SAR) investigations. European Polymer Journal, 46(6), 1251-1267. http://dx.doi.org/10.1016/j. eurpolymj.2010.03.001.

Rabea, E. I., Badawy, M. E.-T., Stevens, C. V., Smagghe, G., \& Steurbaut, W. (2003). Chitosan as antimicrobial agent: Applications and mode of action. Biomacromolecules, 4(6), 1457-1465. http://dx.doi.org/10.1021/bm034130m.

Rabea, E. I., Badawy, M. E. I., Rogge, T. M., Stevens, C. V., Höfte, M., Steurbaut, W., \& Smagghe, G. (2005). Insecticidal and fungicidal activity of new synthesized chitosan derivatives. Pest Management Science, 61(10), 951-960. http://dx.doi.org/10.1002/ ps. 1085 .

Radulescu, M., Ficai, D., Oprea, O., Ficai, A., Andronescu, E., \& Holban, A. M. (2015). Antimicrobial Chitosan based formulations with impact on different biomedical applications. Current Pharmaceutical Biotechnology, 16(2), 128-136.

Rouser, G., Fkeischer, S., \& Yamamoto, A. (1970). Two dimensional then layer chromatographic separation of polar lipids and determination of phospholipids by phosphorus analysis of spots. Lipids, 5(5), 494-496.

Seo, S., King, J. M., Prinyawiwatkul, W., \& Janes, M. (2008). Antibacterial activity of ozone-depolymerized crawfish chitosan. Journal of Food Science, 73(8), M400-M404. http://dx.doi.org/10.1111/j.1750-3841.2008.00922.x.

Seyfarth, F., Schliemann, S., Elsner, P., \& Hipler, U.-C. (2008). Antifungal effect of highand low-molecular-weight chitosan hydrochloride, carboxymethyl chitosan, chitosan oligosaccharide and N-acetyl-D-glucosamine against Candida albicans, Candida krusei and Candida glabrata. International Journal of Pharmaceutics, 353(1-2), 139-148. http://dx.doi.org/10.1016/j.ijpharm.2007.11.029.

Suarato, G., Li, W., \& Meng, Y. (2016). Role of pH-responsiveness in the design of chitosan-based cancer nanotherapeutics: A review. Biointerphases, 11(4), 04B201. http:// dx.doi.org/10.1116/1.4944661.

Sudarshan, N. R., Hoover, D. G., \& Knorr, D. (1992). Antibacterial action of chitosan. Food Biotechnology, 6(3), 257-272. http://dx.doi.org/10.1080/08905439209549838.

Tiera, M. J., Qiu, X.-P., Bechaouch, S., Shi, Q., Fernandes, J. C., \& Winnik, F. M. (2006). Synthesis and characterization of phosphorylcholine-substituted chitosans soluble in physiological pH conditions. Biomacromolecules, 7(11), 3151-3156. http://dx.doi. org/10.1021/bm060381u.

Verlee, A., Mincke, S., \& Stevens, C. V. (2017). Recent developments in antibacterial and antifungal chitosan and its derivatives. Carbohydrate Polymers, 164, 268-283. http:// dx.doi.org/10.1016/j.carbpol.2017.02.001.

Viegas de Souza, R., Takaki, M., de Oliveira Pedro, R., dos Santos Gabriel, J., Tiera, M., \& de Oliveira Tiera, V. (2013). Hydrophobic effect of amphiphilic derivatives of chitosan on the antifungal activity against Aspergillus flavus and Aspergillus parasiticus. Molecules, 18(4), 4437-4450. http://dx.doi.org/10.3390/molecules18044437.

Vieira, N. A. B., Moscardini, M. S., Tiera, V. A.d. O., \& Tiera, M. J. (2003). Aggregation behavior of hydrophobically modified dextran in aqueous solution: A fluorescence probe study. Carbohydrate Polymers, 53(2), 137-143. http://dx.doi.org/10.1016/ S0144-8617(03)00048-1.

Wu, M., Long, Z., Xiao, H., \& Dong, C. (2016). Recent research progress on preparation and application of N, N, N-trimethyl chitosan. Carbohydrate Research, 434, 27-32. http://dx.doi.org/10.1016/j.carres.2016.08.002.

Xing, K., Chen, X. G., Li, Y. Y., Liu, C. S., Liu, C. G., Cha, D. S., \& Park, H. J. (2008). Antibacterial activity of oleoyl-chitosan nanoparticles: A novel antibacterial dispersion system. Carbohydrate Polymers, 74(1), 114-120. http://dx.doi.org/10.1016/j. carbpol.2008.01.024.

Xing, K., Chen, X. G., Liu, C. S., Cha, D. S., \& Park, H. J. (2009). Oleoyl-chitosan nanoparticles inhibits Escherichia coli and Staphylococcus aureus by damaging the cell membrane and putative binding to extracellular or intracellular targets. International Journal of Food Microbiology, 132(2-3), 127-133. http://dx.doi.org/10.1016/j. ijfoodmicro.2009.04.013.

Zasloff, M. (2002). Antimicrobial peptides of multicellular organisms. Nature, 415(6870), 389-395. http://dx.doi.org/10.1038/415389a.

Zwaal, R. F. A., Comfurius, P., \& Bevers, E. M. (2005). Surface exposure of phosphatidylserine in pathological cells. Cellular and Molecular Life Sciences, 62(9), 971-988. http://dx.doi.org/10.1007/s00018-005-4527-3. 